$\xi_{p}$

\title{
Electrodeposition of Co-Ni-Fe on Stainless Steel Bolts
}

\author{
M.S. Md.Nor ${ }^{1}$, Z. Salleh ${ }^{2}$, N. R. N. M. Masdek ${ }^{3}$, Y.M Taib ${ }^{4}$, M.Z. Abu ${ }^{5}$ \\ ${ }_{1,2,3,4}$ Faculty of Mechanical Engineering, Universiti Teknologi MARA, Shah Alam, Selangor, Malaysia \\ ${ }^{5}$ AANS Technical and Services Sdn Bhd, Taman Sri Serdang, Seri Kembangan, 43300 Serdang, Selangor \\ *Corresponding author E-mail: a_kzue@yahoo.com
}

\begin{abstract}
In a fastening system, bolt is the first component to be susceptible to corrosive attack. The focus of the study is to investigate the feasibility of coating stainless steel 304 bolts and the coating properties obtained. In this study, the bolts were coated with cobalt-nickel-iron $(\mathrm{Co}-\mathrm{Ni}-\mathrm{Fe})$ alloy through electrodeposition using platinized titanium as the anodes. The temperature used was $50^{\circ} \mathrm{C}$ and the $\mathrm{pH}$ of the sulphate solution were 2 . The current density was $96.68 \mathrm{~mA} / \mathrm{cm}^{2}$ and deposition time was 30 minutes. The optimum electrodeposition parameters were studied through trial and error. The characteristics of coating such as elemental percentage and microhardness were compared with the substrate. The optimum parameters obtained were current density of $145.01 \mathrm{~mA} / \mathrm{cm}^{2}$, temperature of $60^{\circ} \mathrm{C}$ and 30 minutes of deposition time. The suitable substrate orientation was horizontally hanged and rotated $60^{\circ}$ around screw axis for every 5 minutes. The mean thickness of coating was $117.4 \mu \mathrm{m}$. The coating exhibited $25 \%$ hardness improvement over the substrate. The 2 litres solution could be used for 7.5 hours (15 plating cycles) to produce 15 samples. As a conclusion the surface hardness was not compromised despite that Co-Ni-Fe ions had depleted in the solution.
\end{abstract}

Keywords: Bolt; Co-Ni-Fe; Electrodeposition; Stainless steel 304; Surface properties.

\section{Introduction}

A coating is a covering that is applied to the surface of a substrate. A metallic coating can be formed by various methods such as electrodeposition, galvanizing, painting, etc. Electrodeposition is an electroplating process for producing a dense, uniform and adherent coating. It involves deposition of a metal or alloy coating over a conducting surface by means of electrolysis from a wellformulated electrolyte known as a bath [1], which can be an aqueous solution of a simple salt or a complex salt type.

The study of corrosion resistance material is important because corrosion may cause economics loss, compromise of safety, and failed conservation of equipment [2]. From engineering perspective, the study can increase the lifetime of components exposed to corrosion conditions.

Materials with corrosion resistance properties are prone to the surface damage caused by the environment. Although stainless steel are known for its corrosion resistance, they are susceptible to failure. It affects material properties such as mechanical strength, appearance, and impermeability to liquids and gases. In this study, the selected samples are stainless steel bolts grade 304 that are used in both industrial and commercial.

Among all materials available, the combination of Co-Ni-Fe alloy has a potential to become an alternative coating with good surface properties that comparable to chromium coating [3]. By using electrodeposition, this technique able improve surface properties such as grain size, hardness, and corrosion resistance compared to the parent metals [4]. This study focuses on the optimum electrodeposition parameters and relationship between plating cycle, elemental percentage and surface hardness.

\section{Experimental}

\subsection{Materials}

The selected substrates were tap bolts, stainless steel 304, 1/2"-13 $\mathrm{x} 2$ " UNC. Tap bolt is a sub-category of hex bolt and distinguished as a full thread bolt with a six-sided head as visualised in Fig. 1. The material was made of SAE 304 stainless steel that also commercially known as 18-8 alloy.

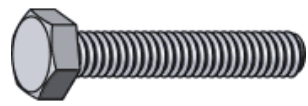

Fig. 1: A 3D model of tap bolt [5]

\subsection{Electrolyte Preparation}

The chemical compounds were prepared according to the required mass tabulated in Table 1. Cobalt sulphate, nickel sulphate and iron sulphate were the sources of metal that produce a $\mathrm{Co}-\mathrm{Ni}-\mathrm{Fe}$ coating layer. Then, the compounds were mixed with 2 litres of distilled water in a beaker with distilled water to create sulfate solution. The $\mathrm{pH}$ of the solution was 2 .

Table 1: Chemical composition of sulfate solution

\begin{tabular}{|c|c|}
\hline Compound & Mass $(\mathrm{g})$ \\
\hline Cobalt Sulphate $\left[\mathrm{CoSO}_{4}\right]$ & 28.12 \\
\hline Nickel Sulphate $\left[\mathrm{NiSO}_{4}\right]$ & 70.08 \\
\hline Iron (II) Sulphate $\left[\mathrm{FeSO}_{4}\right]$ & 11.12 \\
\hline Boric Acid $\left[\mathrm{H}_{3} \mathrm{BO}_{3}\right]$ & 32.96 \\
\hline Ascorbic Acid $\left[\mathrm{C}_{6} \mathrm{H}_{8} \mathrm{O}_{6}\right]$ & 23.48 \\
\hline Saccharin $\left[\mathrm{C}_{7} \mathrm{H}_{5} \mathrm{NO}_{3} \mathrm{~S}\right]$ & 2.72 \\
\hline
\end{tabular}

Copyright $\odot 2018$ Authors. This is an open access article distributed under the Creative Commons Attribution License, which permits unrestricted use, distribution, and reproduction in any medium, provided the original work is properly cited. 


\subsection{Electrodeposition}

The substrates were cleaned using ultrasonic cleaner. They were immersed for 4 minutes in a tank of distilled water heated to $50^{\circ} \mathrm{C}$ Two platinized titanium plates and the substrate were used as anodes and cathode respectively. The initial parameters used prior for any testing was deposition times of 30 minutes at $50 \pm 5{ }^{\circ} \mathrm{C}$, and current density of $96.68 \mathrm{~mA} / \mathrm{cm}^{2}$.

\subsection{Optimum Parameters}

Electrodeposition process parameters are substrate material and shape dependent. Parameters that work for substrate used in previous research might not work in this experiment [2]. The first approach was to study the orientation of bolt during deposition and its effect on the surface finish. The tested orientations were: vertical, vertical upside-down, horizontal and horizontal with rotation. Next, the suitable current density was investigated using current of $0.5 \mathrm{~A}$ first followed by $1.0 \mathrm{~A}, 1.5 \mathrm{~A}$ and $2.0 \mathrm{~A}$. Their respective densities were $48.34 \mathrm{~mA} / \mathrm{cm}^{2}, 96.68 \mathrm{~mA} / \mathrm{cm}^{2}, 145.01 \mathrm{~mA} / \mathrm{cm}^{2}$ and $193.35 \mathrm{~mA} / \mathrm{cm}^{2}$.

Total deposition time that ranged from 15 minutes to 1 hour was tested. The fixed variables were $50 \pm 5^{\circ} \mathrm{C}$ temperature and current density of $96.68 \mathrm{~mA} / \mathrm{cm}^{2}$. The objective was to obtain a good surface finish but did not compromise the tolerance and fit of the bolt to its nut. Since rotating the bolt during deposition had the best result, the deposition time was experimented with various rotation intervals called Method as shown in Table 2.

Table 2: Methods with different deposition time and rotation intervals.

\begin{tabular}{|c|c|l|}
\hline Method & $\begin{array}{c}\text { Deposition time } \\
\text { (minutes) }\end{array}$ & \multicolumn{1}{|c|}{ Remarks } \\
\hline 1 & 60 & $\begin{array}{l}\text { Coated for } 10 \text { minutes for every } \\
60^{\circ} \text { rotation }\end{array}$ \\
\hline 2 & 45 & $\begin{array}{l}\text { Coated for } 15 \text { minutes for every } \\
120^{\circ} \text { rotation }\end{array}$ \\
\hline 3 & 30 & $\begin{array}{l}\text { Coated for } 10 \text { minutes for every } \\
120^{\circ} \text { rotation }\end{array}$ \\
\hline 4 & 30 & $\begin{array}{l}\text { Coated for } 5 \text { minutes for every } \\
60^{\circ} \text { rotation }\end{array}$ \\
\hline 5 & 15 & $\begin{array}{l}\text { Coated for } 2.5 \text { minutes for every } \\
60^{\circ} \text { rotation }\end{array}$ \\
\hline
\end{tabular}

Using the finalized optimum parameters, the process was repeated for a total of 15 plating cycles to create 15 samples. The first bolt was named B0.5, where 0.5 represents the number of hours the solution had been used. This followed by increment of every 0.5 hours until the last sample, B7.5. This means the solution was used for a total of 450 minutes or 7.5 hours cumulatively. Only 6 samples were selected for testing: B0.5, B2.0, B3.5, B5.0, B6.5 and B7.5.

\subsection{Surface Testing}

Hitachi SU3500 SEM was used to investigate surface characteristics of the coating Using a built-in energy-dispersive X-ray spectroscopy (EDX) of the SEM, EDX spectrum of substrate and samples were obtained. Elemental percentage across different cycles of the electrodeposition process was analysed. Micro-hardness testing was carried out using MITUTOYO MVK-H1 by applying a 500 gram load for 15 seconds. The depth of indentation should be less than $1 \mu \mathrm{m}$ to prevent the dent from reaching the substrate [6]. The selected surface was the flat side of the bolt's head. 5 measurements from various locations on the surface were taken for each sample.

\section{Results and Discussion}

\subsection{Optimum Parameters}

\subsubsection{Orientation}

The substrate when it was hanged horizontally during deposition has lesser burn around the threads' valley compared to vertical orientation. However, Fig. 2(a) there was a large burn spot on the upper side of the bolt. This condition is known as poor throwing power and coverage as the setup unable to plate low current density areas with similar thickness as in higher current density areas [7]. The burn was caused by low mass transfer and deposit rate of metals ion that could not catch up the hydrogen discharge rate [8]. Fig. 2(b) shows the burn spot diminished when it was rotated $180^{\circ}$ around screw axis to further coat the upper side. More Co-Ni-Fe was deposited on the burn spot and eventually covered it completely over time. The reason why burn did not form after it was rotated was due to the presence of coating on the substrate, which altered the electrical resistance of substance and helped to stabilise the local current density. This prevented any further burn on the area. Thus, horizontal axis rotation is the suitable orientation to electroplate a bolt.

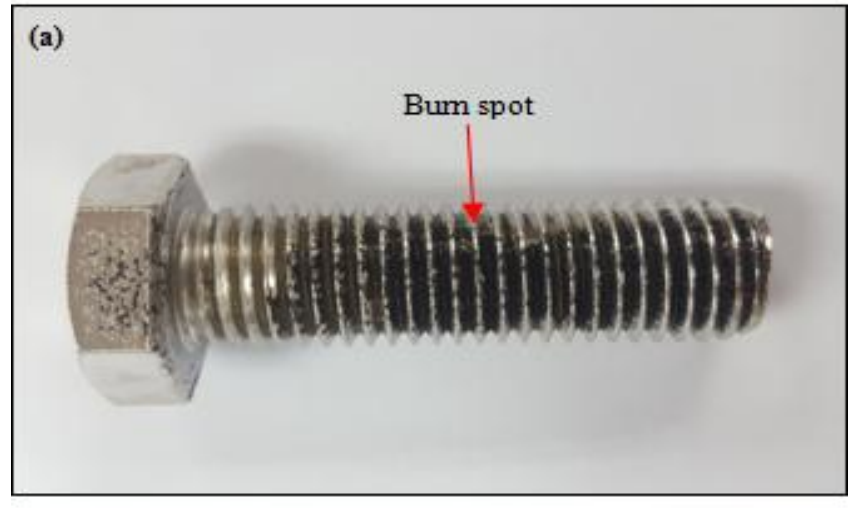

(b)

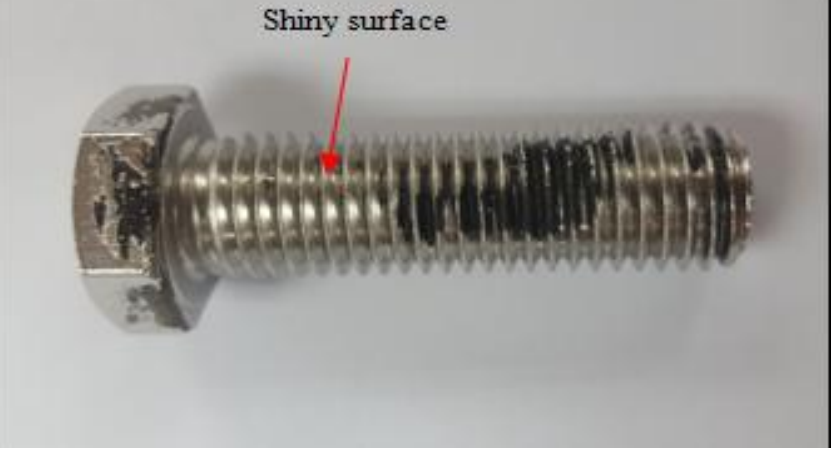

Fig 2: Surface finish when hanged (a) horizontally and (b) horizontally with rotation.

\subsubsection{Current Density}

The current tested were $0.5 \mathrm{~A}, 1.0 \mathrm{~A}, 1.5 \mathrm{~A}$ and 2.0A. Fig. 3(a) shows there are many bubbles coated with $\mathrm{Co}-\mathrm{Ni}-\mathrm{Fe}$ on sample $0.5 \mathrm{~A}$. This phenomenon is known as gassing. No bubbles were formed but the burning on threads is prominent for current $1.0 \mathrm{~A}$. When current $1.5 \mathrm{~A}$ was used, it has the least burning compared to other samples. Current $1.5 \mathrm{~A}$ had the best deposit coverage throughout the threads compared to the rest albeit slightly burn as shown in Fig. 3(b). Thus, it is deduced that 1.5A has a suitable deposition rate. Current density obtained when using $1.5 \mathrm{~A}$ is 145 $\mathrm{mA} / \mathrm{cm}^{2}$. This current density is the exact value used in Koay and Tukiran's work [3]. 


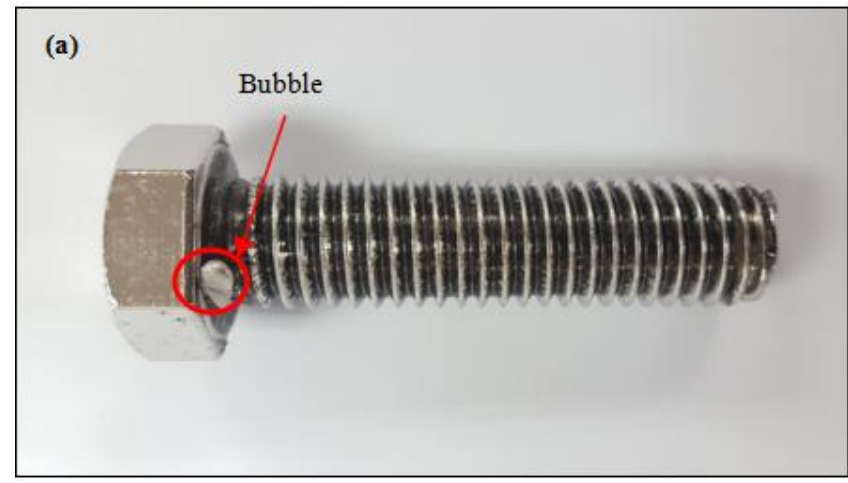

(b)

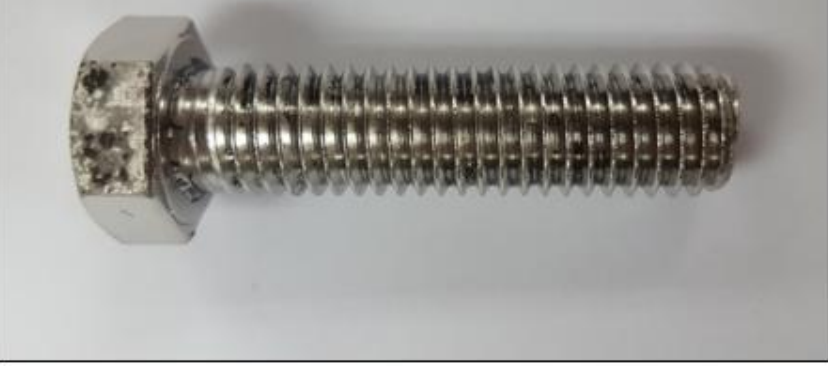

Fig 3: Surface finish of (a) $0.5 \mathrm{~A}$ and (b) $1.5 \mathrm{~A}$.

\subsubsection{Deposition Time}

There were multiple combinations between degree of rotation and the coating time interval as presented in Table 3. Method 1 produced a perfect result but the coating was too thick, which affected the tolerance of bolt with the nut. The head had a pitted deposit. Method 2, 3 and 5 had some burn mark on multiple parts. Only Method 4 produced a notable result that was similar to Method 1 . The only difference was a reduced total deposition time of 30 minutes.

The finding was Method 1 had too long deposition time, which caused the bubbles to stay on the surface longer. The bubbles blocked the metal ions from depositing to the substrate and this phenomenon is known as pitting [9]. Method 2 had burn spots on the ends because current density reduced as the coating got thicker and electrical resistance increased compared to Method 3.

Although Method 3 and 4 had the same total deposition time, Method 3 had burn because the frequency of rotation was lower. This caused the bath solution to be stagnant and metal ions were not dispersed to the burn region [10]. Method 5 had the shortest period between rotations that caused intermittent electricity flow. It is a cause of burnt deposits [11]. Thus, Method 4 was suitable which had the deposition time of 30 minutes and the best work with $60^{\circ}$ rotation for every 5 minutes.

Table 3: Surface finish of different method.

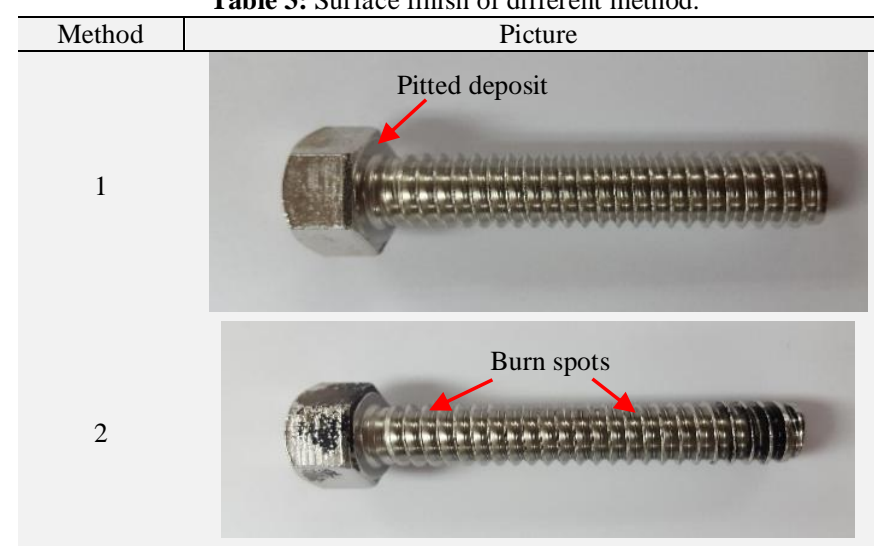

3

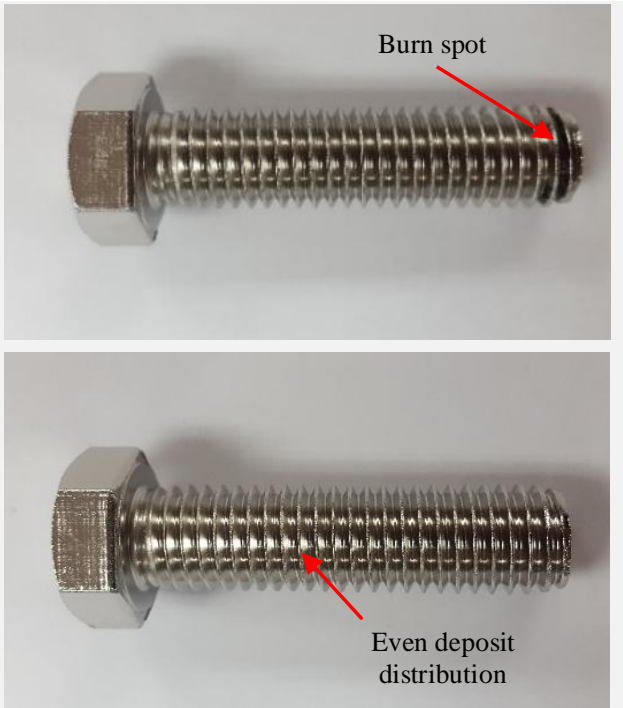

5

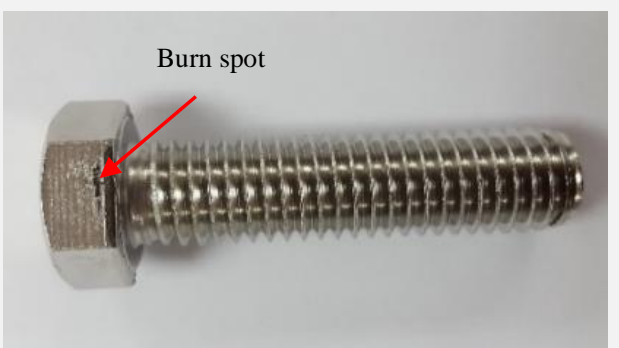

\subsubsection{Finalised Optimum Parameters}

Table 4 shows the finalised parameters that were used for the rest of the experiment to ensure a reproducible result.

Table 4: Finalised coating parameters of the electrodeposition.

\begin{tabular}{|c|c|}
\hline Parameters & Details \\
\hline Arrangement of electrode & $\begin{array}{c}\text { Anode : Platinized titanium } \\
\text { Cathode : Stainless steel 304 bolt }\end{array}$ \\
\hline Temperature $\left({ }^{\circ} \mathrm{C}\right)$ & $60 \pm 5$ \\
\hline $\mathrm{pH}$ value of electrolyte & 2 \\
\hline Current $(\mathrm{A})$ & 1.5 \\
\hline Deposition time $(\mathrm{min})$ & 30 \\
\hline Current density $\left(\mathrm{mA} / \mathrm{cm}^{2}\right)$ & 145 \\
\hline Orientation & Horizontal with rotation \\
\hline
\end{tabular}

\subsection{Plating Cycles}

\subsubsection{Elemental Percentage}

The primary criterion to assess the samples from different plating cycles is to look at their element percentage of coating layer. The primary composition of coating layer consists of cobalt, nickel and iron. EDX spectrum carries reading in terms of weight percentage only whereas the desired value is true weight or mass of elements in the particular spot. Therefore, Co-Ni-Fe alloy weight percentage is normalized with respect to carbon content. This allows a direct comparison between each other and exclusion of minor elements such as platinum and titanium.

Fig. 4 shows that there were $0.4 \%$ platinum and $1.2 \%$ titanium on sample B0.5. The rest of the samples also had those elements with near identical value. These two elements came from the anodes. As the name implies, platinized titanium plate contains platinum and titanium. This is caused by a phenomenon known as reduction of ions that occurs at cathode where the material gains electrons [13]. Platinum and titanium are deposited in small quantity during plating process.

The presence of fluorine (F) at the highest peak in EDX spectrum in Fig. 5 is caused by the limitation of the equipment. The reason 
of the problem is that the difference in energy of the $\mathrm{X}$-ray lines for F-K (F-K $\alpha 677 \mathrm{eV})$ and Fe-L $(\mathrm{Fe}-\mathrm{L} \alpha \mathrm{704 \textrm {eV }})$ is only $27 \mathrm{eV}$ [14]. This value is very close but the issue is addressable by using WDS spectrometer to verify the presence of fluorine.

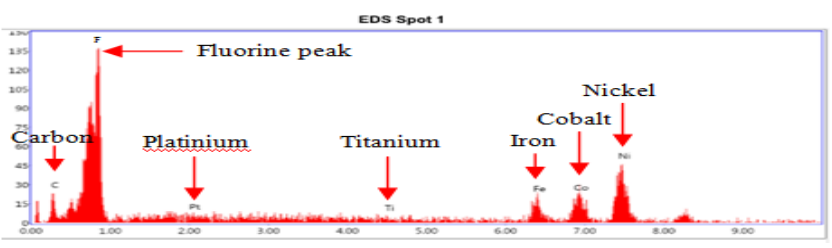

Fig. 4: EDX spectrum of sample B0.5.

Fig. 5 shows the Co-Ni-Fe and carbon percentages in the substrate and other samples. Stainless steel 304 mainly consists of iron and the others make of $20 \%$ only. On the other hand, all $\mathrm{Co}-\mathrm{Ni}-\mathrm{Fe}$ coated samples have iron content of less than $15 \%$. Elements percentage of sample B 0.5 tally to the ratio of electrolyte compound Cobalt Sulfate (28.12 g), Nickel Sulfate (70.08 g) and Iron (II) Sulfate (11.12 g).

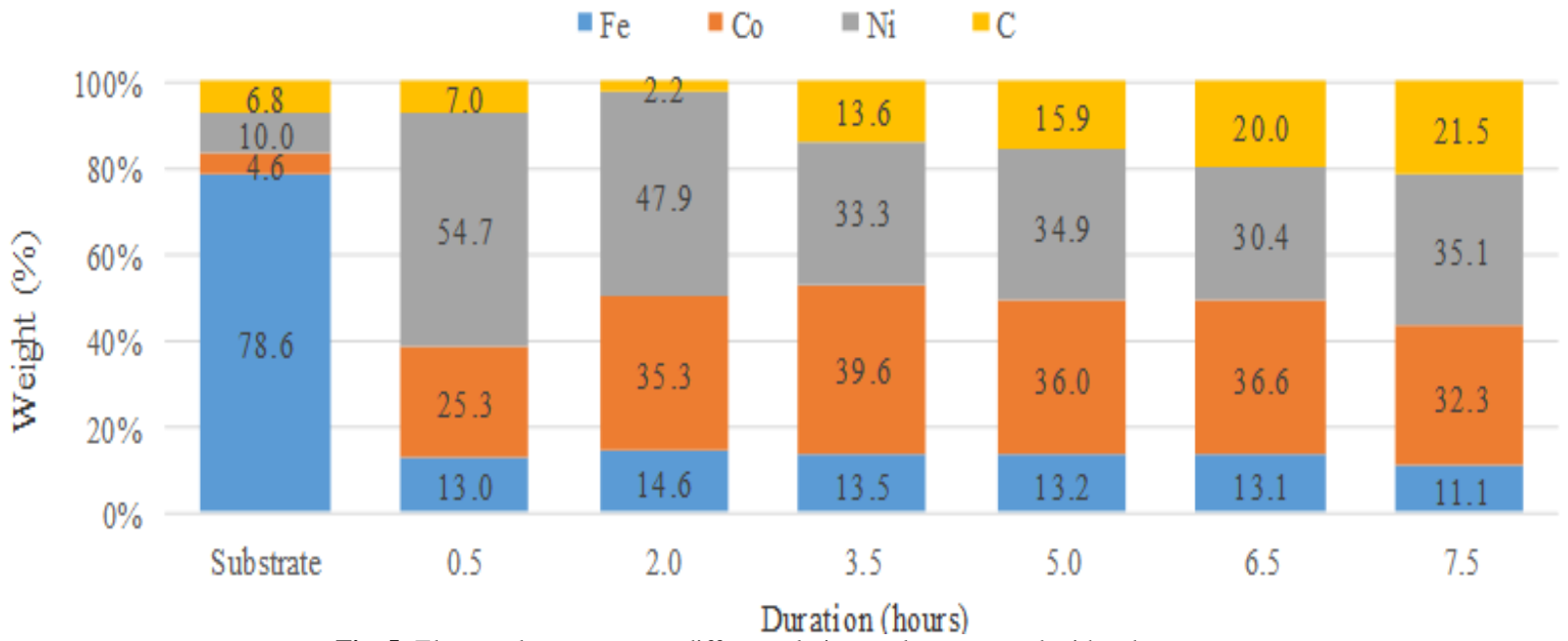

Fig. 5: Elemental percentage at different plating cycles compared with substrate.

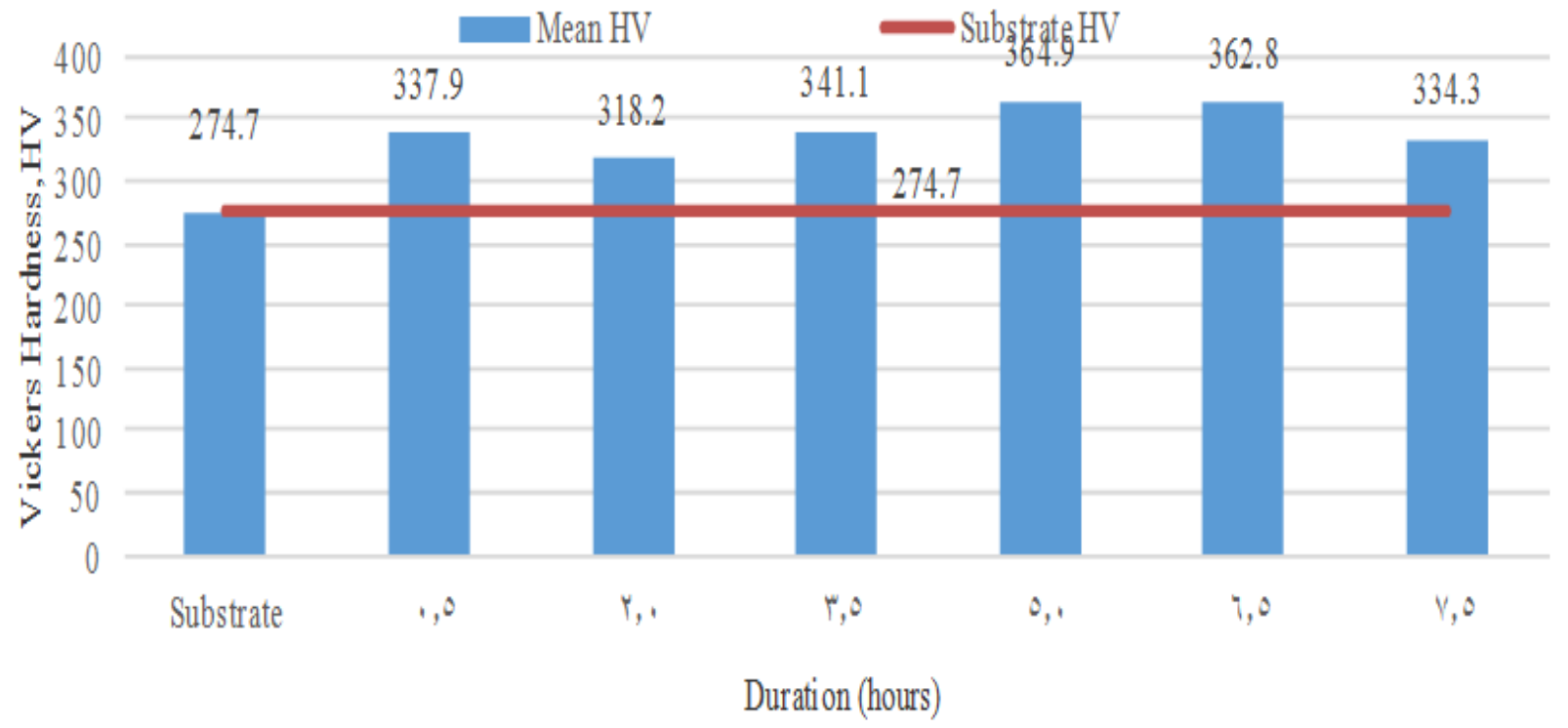

Fig. 6: Microhardness at different plating cycles compared with substrate.

This ratio was also found in sample B0.5 as the nickel had the highest content. However, the nickel percentage started to drop during plating cycle at 3.5 hours. The trend continued towards thefinal cycle as the total percentage of Co-Ni-Fe dropped $14.5 \%$ from the first cycle that had $93 \%$ Co-Ni-Fe. This signified that as the three metals depleted, carbon has taken up their place in terms of element percentage. The carbon inclusion in the coating results in increased impurity-based electron and a change in microstructure [12].

\subsubsection{Microhardness}

Fig. 6 presents their hardness value and standard deviation in Vickers Hardness number which is compared with substrate's hardness. It indicated that stainless steel sample had $274.7 \pm 56.5$ HV which was higher than ASM recorded (129 HV) [15]. The heat treatment process during bolt manufacturing could increase the hardness [16]. 
Sample B0.5 demonstrated a higher surface hardness with an increase of $63.2 \mathrm{HV}$ over the substrate. For unknown reason, there was a drop in hardness value on sample B2.0 but remained above the substrate hardness. Then, the hardness bounced back as the duration entered 3.5 hours while the $5^{\text {th }}$ hours was the peak of hardness at $364.9 \pm 21.3 \mathrm{HV}$. The hardness declined beyond $5^{\text {th }}$ hour of solution usages. The average hardness of all samples was $343.2 \mathrm{HV}$. This result was verifiable with previous research of Koay et al. that obtained microhardness of $267.8 \mathrm{HV}$ [17].

Hence, Co-Ni-Fe has an improved surface hardness compared to stainless steel 304 generally. Around 5 and 6.5 hours of deposition on multiple samples using the same solution with bolts electroplated within that particular cycles is the preferred batch. Besides, Fig. 6 does not correlate to the carbon content presented in Fig. 4 from elemental percentage sub-topic. Hence, carbon content neither increase nor decrease the microhardness of $\mathrm{Co}-\mathrm{Ni}-\mathrm{Fe}$.

\section{Conclusion}

Electrodeposition of Co-Ni-Fe on stainless steel bolts is a feasible surface finishing process. The suitable orientation is to hang horizontally with rotation of $60^{\circ}$ about its screw axis for every 5 minutes. This brings a total deposition time of 30 minutes for one complete revolution. This method produces a surface finish with minimal burn spot. Deposition time of 30 minutes with current density of $145 \mathrm{~mA} / \mathrm{cm}^{2}$ had sufficiently produced a Co-Ni-Fe coating that exhibited good surface properties. EDX spectrum shows that the Co-Ni-Fe ions deplete over the duration of 7.5 hours plating cycle and yet the average hardness of all samples is 343.2 HV, which remains higher than stainless steel. Hence, electrodeposition of $\mathrm{Co}-\mathrm{Ni}-\mathrm{Fe}$ on stainless steel bolts is feasible and the solution could be used for 7.5 hours plating cycle without compromising the coating properties. The sample of the first plating cycle should be discarded due to surface burning. Only samples from the second to fifteenth plating cycles are suitable for future research and testing.

\section{Acknowledgement}

This work was supported by the research grant no. 100-IRMI/PRI 16/6/2 (012/2018) under the Institute of Research Management \& Innovation, Universiti Teknologi MARA and Faculty of Mechanical Engineering, Universiti Teknologi MARA for providing equipment and other supports to conduct this research. The authors would also like to gratefully acknowledge the financial support from 'Geran Penyelidikan dan Pengkomersialan Vendor' and the help of AANS Technical and Services Sdn Bhd for their technical support.

\section{References}

[1] F. A. Lowenheim and S. Senderoff, Modern Electroplating, vol. 111, no. 11. 1964

[2] R. W. Revie and H. H. Uhlig., Corrosion and Corrosion Control: An Introduction to Corrosion Science and Engineering, 4th Edition. 2008.

[3] M. H. Koay, M. A. A. Tukiran, S. N. A. Mohd Halidi, M. Che Murad, Z. Salleh, and H. Yusoff, "Corrosion investigation of $\mathrm{Co}-$ $\mathrm{Ni}-\mathrm{Fe}$-coated mild steel electrodeposited at different current densities and deposition times," Ind. Lubr. Tribol., vol. 69, no. 3, pp. 393-398, 2017.

[4] K. M. Hyie, M. Z. Zabri, N. R. Nik Roseley, and N. R. Nik Mohd Masdek, "Effect of deposition time on wear and corrosion performance of Co-Ni-Fe alloy coated mild steel," J. Mater. Res., vol. 31, no. 13 , pp. 1848-1856, 2016.

[5] Bolt Depot Inc., "Tap bolts." [Online]. Available: https://www.boltdepot.com/Tap_bolts.aspx. [Accessed: 21-Apr2018].

[6] C. Evans, Metrology and properties of engineering surfaces, vol. 1, no. 3. 1979.
[7] Plating Resources Inc., "Poor Throwing Power \& Coverage." [Online]. Available: http://www.plating.com/platingtechnical/poorthrowingpower.htm. [Accessed: 09-Jun-2018].

[8] T. Winn, "What Is 'Burning' from a Plating Bath?," 2016. [Online]. Available: https://www.asterionstc.com/2016/04/burning-platingbath/. [Accessed: 27-Jun-2018].

[9] "Brass Electroplating." [Online]. Available: http://shodhganga.inflibnet.ac.in/bitstream/10603/181590/6/06_cha pter 3.pdf. [Accessed: 20-Apr-2018].

[10] M. Carano, "Trouble in Your Tank: Acid Copper Plating," 2017. [Online]. Available: http://pcb.iconnect007.com/index.php/article/102516/trouble-inyour-tank-acid-copper-plating/102519/?skin=pcb. [Accessed: 04May-2018].

[11] N. Once, "5 Troubleshooting," pp. 40-41.

[12] T. George, K. Son, B. Eyre, O. Orient, M. Jpl, P. K. Nobe, P. Sumodjo, D. Park, and B. Yoo, "Development of electroplated magnetic materials for MEMS,” J. Magn. Magn. Mater., vol. 265, no. 2, p. 192, 2003.

[13] Lumen Learning, "Predicting the Products of Electrolysis." [Online]. Available: https://courses.lumenlearning.com/boundlesschemistry/chapter/electrolysis/. [Accessed: 13-May-2018].

[14] AZoM, "Using EDS and WDS for the Examination of the Fluorine $\mathrm{K}$ Line and Iron L Line Overlap." [Online]. Available: https://www.azom.com/article.aspx?ArticleID=11971. [Accessed: 20-May-2018].

[15] P. Harvey, Engineering Properties of Steel. 1982.

[16] AZoM, "Stainless Steel - Heat Treatment," 2002. [Online]. Available:

https://www.azom.com/article.aspx?ArticleID=1141\#hardening. [Accessed: 07-Jun-2018].

[17] K. M. Hyie, N. A. Resali, and W. N. R. Abdullah, "Study of Alloys Addition to the Electrodeposited Nanocrystalline Cobalt," Adv. Mater. Res., vol. 486, pp. 108-113, 2012. 